\title{
La musicoterapia, una vía de expresión global
}

\author{
Isabel Agudo CADARso ${ }^{1}$ \\ isabelagudo@cmtb.net
}

Recibido: 8-11-15

Aceptado: 23-11-15

\section{Resumen}

La Musicoterapia se ha revelado últimamente como una herramienta de intervención efectiva en la prevención y rehabilitación de patologías muy diversas, ayudando a mantener o mejorar las funciones físicas, psico-emocionales y sociales de las personas. En este articulo explicamos cómo se articula una intervención en Musicoterapia partiendo del conocimiento de los efectos de la música en el ser humano y cómo estos llegan de una manera global a todas las áreas de la persona y utilizando adecuadamente las diferentes técnicas de musicoterapia basadas en la escucha y la improvisación musical, podemos influir en el bien estar de nuestros pacientes o clientes.

Palabras clave: Música; terapia; expresión; intervención; musicoterapia.

\begin{abstract}
Musictherapy has lately emerged as a tool for effective intervention in the prevention and rehabilitation in a variety of pathologies, helping to maintain or improve psycho-emotional, social and physical functions of individuals. This article explains how an intervention is articulated in Music Therapy from knowledge about the effects of music on human beings and how these come in a comprehensive manner to all areas of the person and properly using different techniques based music therapy listening and musical improvisation, we can influence the well being of our patients or clients.
\end{abstract}

Music Therapy, a way of Global Expression

Keywords: music; therapy; expression; intervention; music therapy.

\section{Introducción}

La música nos ofrece una vía de expresión emocional muy importante y necesaria para vivir y a la vez que nos deleita nos ayuda a desarrollar capacidades cognitivas y habilidades sociales. Son los múltiples usos de la música en la sociedad lo que nos hace reflexionar sobre su poder terapéutico. Desde los inicios de la humanidad el ser humano ha tenido una necesidad interior de expresar sus sentimientos más íntimos y exteriorizarlos de manera artística y compartir sus pensamientos y los de toda una comunidad con el mundo. Se cree que la música fue una de las primeras manifestaciones artísticas para exteriorizar esos sentimientos. Rodeados por sonidos 
de la naturaleza el ser humano ha intentado desde sus orígenes, reproducirlos y comunicarse y relacionarse de alguna manera con los sonidos creados.

Partimos del principio de que somos seres musicales, y seres rítmicos como lo muestra el ritmo de la respiración, el ritmo cardiaco, el del sueño y la vigilia y los ritmos vitales.

Somos nuestro cuerpo, y por tanto a través de él nos manifestamos, el sonido es un fenómeno físico una vibración que estimula nuestro cerebro poniendo en funcionamiento miles de conexiones que nos llevan a movernos físicamente, emocionalmente, cognitivamente y espiritualmente.

Nuestro cuerpo ante el estimulo sonoro se convierte en resonador de las vibraciones musicales afectando nuestro sistema motor y límbico.

Hacer música refuerza la voluntad, la autoestima y, nos conecta con una fuente de evasión y placer que puede aumentar la salud y la calidad de vida. Se trata de un proceso global y dinámico que compromete al individuo por entero.

La música tiene la capacidad de "mover" al ser humano tanto en el ámbito físico como emocional. Así mismo, la activación emocional y corporal y el desarrollo de las capacidades de expresión y comunicación a través de experiencias musicales y corporales, ayudan a mejorar los aspectos cognitivos y de competencia para el manejo de las relaciones sociales.

En Musicoterapia utilizamos la música para mantener o mejorar nuestra salud. Una actividad musical planteada de manera adecuada nos puede ayudar a trabajar determinados aspectos de nuestra persona. A través de experiencias sonoro musicales se establece o restablece la comunicación, éstas se experimentan como lenguaje, enmarcándose en el campo de la socialización. Buscamos "la manera de existir" de cada uno, según sus circunstancias vitales y ambientales, y potenciamos la expresión. Usamos instrumentos de percusión, melódicos, el cuerpo, la voz y todo aquello que nos permita establecer un vínculo.

Por medio de la intervención en Musicoterapia logramos que las personas tomen conciencia de sus recursos motores, cognitivos, emocionales y relacionales, los cuales pueden ser mantenidos, desarrollados, mejorados y potenciados.

Consiste en "un proceso dirigido, en el que el terapeuta ayuda al paciente o cliente a acrecentar, mantener o restaurar un estado de "Bienestar" utilizando "experiencias musicales" y las relaciones que se desarrollan a través de ellas como fuerzas dinámicas de cambio.”(Bruscia. K. 1999)

La música es un lenguaje universal y familiar; es un lenguaje que funciona a un nivel no verbal, que ayuda a abrir nuevos canales de comunicación, especialmente en aquellos casos en que las funciones expresivas y de lenguaje se encuentran deterioradas o bloqueadas (Benenzon. R .1980) Una adecuada audición musical aporta estructura y orden, y este orden da seguridad a quien lo escucha. Además, es una experiencia estética que cautiva a las personas, aportando una experiencia agradable y positiva.

La música afecta, de una manera global a todas las áreas del ser humano (Poch. S.1999)

En el área físico-corporal, el ritmo de la música por empatía afecta e influye 


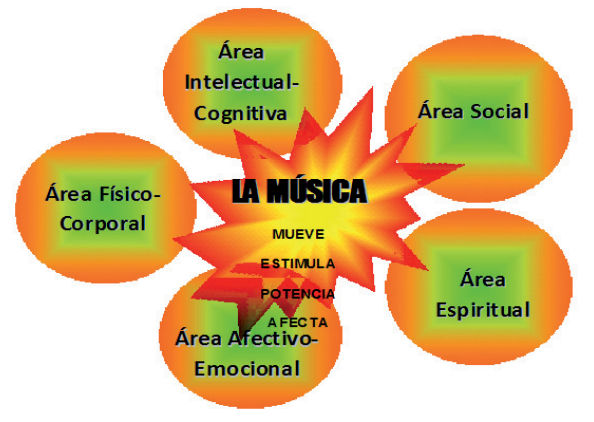

en todos nuestros ritmos corporales, en el pulso cardiaco, en la presión sanguínea y en el ritmo respiratorio así como también en la respuesta galvánica de la piel, todos recordamos aquellas ocasiones en que al escuchar una música se nos pusieron los pelos de punta, y la sensación que esto nos produjo.

Las respuestas músculo-motrices hacia la música son conocidas por su efectividad en la actividad muscular, es evidente que

nos ayuda a anticipar, organizar y sincronizar el movimiento, por tanto nos resulta mucho más fácil y eficaz realizar las actividades motrices funcionales, (andar, correr, saltar...) y también conseguimos mejorar y controlar la respiración influyendo en el tono muscular y facilitando conseguir la relajación apoyándonos en ritmos lentos y melodías suaves.

En el área afectivo -emocional, puede despertar, evocar, provocar, fortalecer y desarrollar cualquier emoción o sentimiento humano (amor, odio, tristeza, alegría, desesperación, temor, miedo, angustia, etc.) La música puede provocar efectos sedantes, estimulantes, enervantes, ...y nos puede ayudar a identificar y reconocer nuestros sentimientos y facilitar su expresión. (Thaut, 1989).

A nivel cognitivo, todos conocemos la capacidad de captar la atención de la música por tanto una de sus aplicaciones terapéutica será desarrollar la capacidad de atención sostenida y así poder facilitar el aprendizaje y desarrollar el sentido del orden y del análisis.

Escuchar una canción o pieza musical preferida nos trae recuerdos y estimula la memoria, nos retorna a momentos felices, mueve nuestra imaginación y la capacidad creadora.

Desde el punto de vista social observamos que es un gran agente socializador, facilita el dialogo, favoreciendo las relaciones sociales y el sentimiento de pertenencia a un grupo, es un medio de encuentro, evasión, alegría y placer. "la música es terapéuticamente eficaz porque es la más social de todas las artes, y son precisamente estos aspectos sociales de la vida los que están afectados por la enfermedad."( McClosky .1985),

En todas las culturas encontramos música religiosa especialmente creada para alabar y comunicarnos con Dios o para despedirnos de nuestros seres queridos en la hora de la muerte. Sin duda afecta a nuestra espiritualidad, es el lenguaje de comunicación con lo sublime, puede sugerir o evocar sentimientos religiosos o que trascienden al hombre, invitar a la reflexión y a crear ambiente para la meditación.

La investigación ha demostrado que todas las personas tienen tanto el interés como la capacidad de desarrollar actividades musicales. Un programa correcto de Musicoterapia incluye oportunidades no solamente para escuchar la música, sino también para cantar, crear, interpretar y moverse a través de ella. Por medio de la intervención en Musicoterapia logramos que las personas tomen conciencia de sus 
recursos motores, cognitivos, emocionales y relacionales, los cuales pueden ser mantenidos, desarrollados, mejorados y potenciados.

Por tanto nuestra intervención se articula basándonos en el conocimiento de los efectos que produce la música sobre el ser humano y de Las técnicas de musicoterapia que utilizaremos para ayudar a nuestros pacientes según sus necesidades, proporcionándoles experiencias musicales cómo facilitadoras de procesos expresivos y comunicativos que les ayuden a encontrar nuevas vías de expresión y creación de uno mismo.

\section{Técnicas y audiciones}

Las técnicas de Musicoterapia que utilizamos partiendo de las necesidades singulares de nuestros pacientes las podemos clasificar en dos categorías:

1.- Pasivo - Receptiva basadas en la audición musical y en la escucha

2.- Activo - Creativas basadas en la improvisación musical, en el hacer y crear música: Con nuestra voz que es el instrumento musical que todos tenemos. (Improvisación vocal, Canciones -coros). Con nuestro cuerpo, (improvisación corporal): Danza creativa -bailes. (Improvisación instrumental) Improvisaciones Rítmicas y creaciones musicales.

Las Audiciones tienen como objetivos específicos la estimulación de imágenes, fantasías y recuerdos. A través de ellas podemos desarrollar la capacidad de atención, concentración y memoria (Gibbons, 1977). Facilitar el conocimiento emocional a través del lenguaje simbólico de la música así como la expresión y la comunicación verbal y escrita. Facilitar la relajación, y brindar una experiencia estética, positiva y agradable. Durante las audiciones se utiliza tanto música grabada elegida por los propios pacientes y por el terapeuta cómo música en vivo, se escucha música de todos los estilos dependiendo de las preferencias de los pacientes y sus necesidades. "La mayoría de las personas tiene una relación con la música basada en la escucha, en la audición. Si no tenemos en cuenta ese aspecto y basamos nuestra práctica exclusivamente en el hacer musical, estamos ignorando una parte importante de toda la relación que tienen las personas con la música." (Schapira, 2007)

Improvisación musical con la voz. Cantar ayuda a salir de situaciones negativas y a sacar la agresividad, transformándola. Ayuda al paciente a aumentar su capacidad respiratoria y a que sea capaz de expresarse musicalmente así como reforzar la memoria y resolver problemas de lenguaje (Poch.S, 1999). El cantar en grupo engendra una gran fuerza socializadora y de comunicación reforzando la seguridad en uno mismo y la autoestima. El canto sublima sentimientos y emociones y refleja nuestro estado de ánimo. Las canciones se vuelven la segunda voz del terapeuta y en ocasiones son la manifestación de lo que oculta o siente el paciente.

Improvisación musical con instrumentos. A través de sensibilización y exploración de distintos instrumentos musicales, trataremos de encontrar que cualidades de música motivan y estimulan al paciente. Trabajaremos el ritmo y la melodía y fomentaremos la libertad de expresión, la creatividad, ayudando al paciente a expresarse musicalmente reforzando la relación y comunicación entre ellos. "En la improvisación, el paciente va a encontrar una experiencia útil y liberadora de 
emociones contenidas. Las improvisaciones musicales terapéuticas no deben buscar el desarrollo de una experiencia musical con fines estéticos, sino la revelación de la estructura de la personalidad de ese sujeto y por ello la función estaría centrada en posibilitar el despliegue de contenidos internos a partir de la experiencia musical." (Schapira, 2007)

Improvisación y expresión corporal: música y movimiento. La música nos ayuda a movilizar todas nuestras articulaciones corporales, haciendo sentir las posibilidades de movimiento de cada una de ellas. Así podemos desarrollar la capacidad expresiva y de movilidad corporal y tomar conciencia de nuestro cuerpo y de sus posibilidades de movimiento y de comunicación y desarrollar técnicas de representación que impliquen el cuidado del gesto tan importante en nuestras relaciones sociales.

Expresarse a través del cuerpo sintiendo la música que nos mueve, potencia y desarrolla la capacidad imaginativa y creadora de las personas que a través de la danza y de juegos de comunicación y expresión corporal toman conciencia de si mismos y de los demás. La danza el baile y las coordinaciones rítmicas nos hacen lliberar tensiones y nos preparan para alcanzar más fácilmente la relajación corporal y psíquica. La música junto con el ritmo corporal de la respiración induce a la relajación y ayuda a controlar los estados de ansiedad y situaciones de estrés.

En cuanto a las funciones de la música en musicoterapia ,la utilizamos para potenciar la empatía entre los miembros de un grupo, facilitar la expresión emocional (musical, verbal o no verbal), promover la interacción (dar y recibir) mediante la creación y la escucha, posibilitar la comunicación (intercambio de ideas y sentimientos), animar a la exploración (desde la vivencia se observan las alternativas y posibilidades de cambio), realizar conexiones (mentales-corporales-sensorialeshistoria familiar, etc.) para volver a poner las partes en un "todo armonioso", reparar (la experiencia musical puede ayudar al sujeto a encontrarse con sus necesidades y proveerle de lo que ha sido privado), validar a la persona fortaleciendo su autoestima y autoconfianza (la música ofrece sostén emocional y reafirma), influenciar mediante actividades que provean de insight e induzcan los cambios y motivar, las actividades transcurren en la música lo que la convierte en agente motivador que permite explorar nuevos horizontes y encontrar nuevas vías de realización personal.

\section{Conclusión}

La música tiene capacidad para producir efectos simultáneos en todas las áreas de la persona, (Taylor, 1989. Poch ,1999)) esto permite al musicoterapeuta diseñar experiencias musicales que basadas en las capacidades del paciente le permitan a la vez incidir sobre el área más necesitada.

Está presente en todas las culturas conocidas, y forma parte en todos los acontecimientos importantes de la vida en cada comunidad, (Sneidher. 1956), es un arte "accesible" a los individuos, de manera que la mayoría de las personas han tenido experiencias musicales.

La flexibilidad de la música permite adaptarse a diferentes niveles y objetivos, según las necesidades del paciente, lo que facilita que éste tenga experiencias positivas y satisfactorias sea cual sea su grado de habilidad o capacidad. 
En musicoterapia es fundamental conocer los gustos y preferencias musicales del paciente o grupo con el que trabajas, la música preferida posee mayor capacidad para provocar una mayor motivación e implicación y por tanto facilitará el proceso terapéutico.

Como todas las artes, proporciona una experiencia estética, que vivida satisfactoriamente puede llevar a la autorrealización de la persona y a mejorar su autoestima y paralelamente contribuir a una mayor calidad de vida.

\section{Bibliografía}

ALVIN, J. (1997), Musicoterapia. Editorial Paidós, Barcelona

BENENZON, R. (2000), Musicoterapia. De la teoría a la práctica. Editorial Piadós, Barcelona.

BETÉS DE TORO, MARIANO (2000), Fundamentos de Musicoterapia. Editorial Morata, Madrid.

BRUSCIA, KENNETH (1999), Modelos de improvisación en musicoterapia. Editorial Agruparte, Vitoria-Gasteiz.

BRUSCIA, KENNETH (1997), Definiendo musicoterapia. Colección Música, Arte y Proceso. Amarú Ediciones, Salamanca

DAVIS, W.B.; GFELLER, K.E.; THAUT, M.H. (2000), Introducción a la musicoterapia. Teoría y práctica. Boileau, Barcelona.

GASTÓN, E. THAYER (1968), Tratado de Musicoterapia. Ed. Paidós.

PELLIZZARI, P. Y RODRÍGUEZ, R. (2005). Salud, escucha y creatividad. Buenos Aires: EUS

POCH BLASCO, SERAFINA (1999), Compendio de Musicoterapia, vol. I y II. Editorial Herder, Barcelona.

RUUD, EVEN (1993), Los caminos de la musicoterapia: la musicoterapia y su relación con las teorias terapéuticas actuales. Editorial Bonum, Buenos Aires.

SCHAPIRA, D., FERRARI, K., SÁNCHEZ, V., Y HUGO, M. (2008). Musicoterapia. Abordaje plurimodal. Buenos Aires: UBA

TAYLOR, DALE B. (1997), Biomedical Foundations of Music as Therapy. MMB Music, Saint Louis.

\section{Revistas:}

Journal of Music Therapy. American Association for Music Therapy. (www.amta. org).

British Journal of Music Therapy. (www.hisf.no/nimt/journals.html).

Música, Arte y Proceso (www.aqruparte.com/agruparte.pag 02b.html).

Music Therapy Perspectives. NAMT.

\section{Webs con información sobre musicoterapia:}

www.musictherapyworld.net (Información sobre musicoterapia a nivel mundial) www.musictherapy.org (AMTA)

www.musictherapy.com (Información sobre musicoterapia)

www.agruparte.com (Instituto de Música, Arte y Proceso de Vitoria) 
www.atame.org (letras y acordes de canciones españolas, cursos de guitarra...). www.softcatala.org (Music Time: programa gratuito para componer música). www.musicoterapia.com.mx (Instituto de Musicoterapia y Terapias centradas en la Música)

www.musicoterapianorte.com.ar (Información, links y foros sobre musicoterapia)

\section{Notas al pie}

1. Profesora de Educación Primaria, Licenciada en Historia, diplomada en Piano, Musicoterapeuta, especialista en Salud Mental. Directora del centro de Musicoterapia de Barcelona, Coordinadora del Master de MT de ISEP, (Barcelona).Ex-presidenta de la Asociación Catalana de Musicoterapia.(2007-2013) 